\title{
Clinical Profile of Episodic Wheezing and Multiple Trigger Wheezing in Preschool Children: A Cross-Sectional Study
}

\author{
Lalsiama Tualzik ${ }^{1}$ Venkatesh Chandrasekaran ${ }^{2}$ \\ ${ }^{1}$ Department of Pediatrics, District Hospital Mamit, Mizoram, India \\ 2 Department of Pediatrics, Jawaharlal Institute of Postgraduate \\ Medical Education and Research, Puducherry, India \\ J Child Sci 2020;10:e141-e147.
}

\begin{abstract}
Keywords

- atopy

- children

- EVW

- MTW

- phenotype

- preschool

- wheeze
\end{abstract}

Address for correspondence Venkatesh Chandrasekaran, DNB Pediatrics, MNAMS, Department of Pediatrics, Jawaharlal Institute of Postgraduate Medical Education and Research, Dhanvantri Nagar, Puducherry 605006, India (e-mail: cvenkatesh@hotmail.com).

\section{Introduction}

Preschool wheezers are twice more likely to visit hospitals and thrice more likely to be admitted compared with older children. ${ }^{1}$ An essential requirement for better management of these children is to classify them as either episodic viral wheezers (EVWs) or multiple trigger wheezers (MTWs) based on European Respiratory Society (ERS) Task Force recommendations 2008. ${ }^{2}$ Although these phenotypes were found by some authors to change over time, ${ }^{3-5}$ a recent study by Spycher et al indicates that they remain stable. ${ }^{6} \mathrm{~A}$ significant number of them, particularly the MTW, are likely to have symptoms consistent with asthma and reduced lung capacity later in life., ${ }^{7,8}$ The identification of these phenotypes help in predicting long-term outcomes and also to identify high-risk children who might benefit from secondary preventive interventions. There are only few studies comparing the clinical and sociodemographic

received

July 26,2020

accepted after revision

August 20, 2020
DOI https://doi.org/

10.1055/s-0040-1717140. ISSN 2474-5871. profiles of these two phenotypes and none among Indian children. Hence, this study was performed to identify the relative frequency of EVW and MTW in preschool children 1 to 5 years of age with wheezing and to compare the relevant clinical and sociodemographic parameters in the above phenotypes.

\section{Methods}

This cross-sectional study was conducted in the Department of Pediatrics, Jawaharlal Institute of Postgraduate Medical Education and Research, Puducherry, a tertiary care teaching institute from December 2015 to December 2017 after obtaining approval from our institute ethics committee. Preschool children (1-5 years of age), who were on followup in the childhood asthma clinic for at least 3 consecutive months and diagnosed by a doctor to have recurrent wheeze participated in this study. Children with pneumonia, history
Copyright $\odot 2020$ Georg Thieme Verlag License terms
KG Stuttgart · New York 
suggestive of gastroesophageal reflux disease, congenital heart disease, stridor, history suggestive of foreign body, bronchopulmonary dysplasia, bronchiectasis, immunodeficiency, and anatomic abnormalities leading to recurrent aspiration were not enrolled.

We recruited 165 children, who fulfilled the inclusion criteria during the study period ( - Fig. 1). The participants were classified into EVW and MTW as per ERS Task Force guidelines 2008. Children who had history of wheezing during discrete time periods, following viral infections, with absence of wheeze between episodes were categorized as EVW. Children who had history of discrete exacerbations of wheeze and also had symptoms in between episodes of viral infections were categorized as MTW. ${ }^{2}$

For all participants, data on rural or urban location and parental literacy were recorded. Socioeconomic status (SES) was classified based on modified Kuppuswamy scale 2014. ${ }^{9}$ History regarding the age of onset, frequency of symptoms, bronchiolitis in the past, frequency of wheeze exacerbations, triggers, seasonality, personal and family history of atopy, exposure to environmental smoke, prematurity, low birth weight, neonatal respiratory distress, breastfeeding status, immunization status, investigation, and treatment details were noted. Weight and height were measured and classified according to the World Health Organization guidelines. ${ }^{10}$ Symptom control was assessed based on Global Initiative for Asthma (GINA) 2015 guidelines. ${ }^{11}$ In our study, we classified the well-controlled symptom group in GINA 2015 as "well-controlled symptom group" and the partly and uncontrolled groups together as "uncontrolled symptom group." The Institute Ethics Committee-Human Studies of our institute approved the study (JIP/IEC/2015/22/776).

\section{Statistical Analysis}

Continuous variables were expressed as median with interquartile range (IQR). Categorical variables were expressed as proportions. Mann-Whitney's $U$ test was done for quantitative variables and chi-square test was used for categorical variables. Multiple logistic regression analysis was done for factors associated with symptom control for both EVW and MTW and also

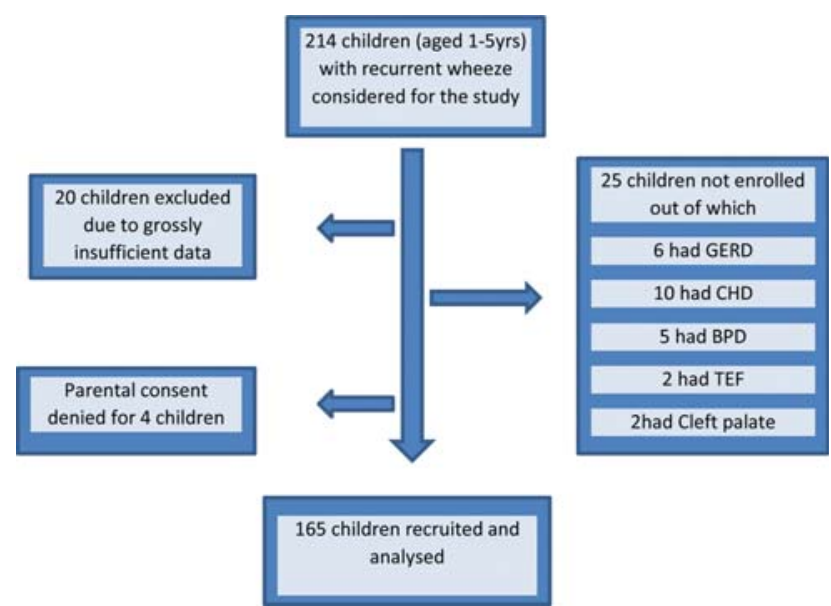

Fig. 1 Study flow diagram depicting the inflow of subjects into the study. for all the participants combined. For statistical analysis, Statistical Package for the Social Sciences (SPSS) version 19 by International Business Machines (IBM) Corporation was used.

\section{Results}

The median age of the study population was 42 months with an IQR of 27.5 to 51.5. Boys were 110 (66.7\%) in number; children belonging to rural areas were 98 (59.4\%). Two children (1.2\%) belonged to lower, 38 (23\%) belonged to upper lower, $72(43.8 \%)$ belonged to lower middle, 35 (21\%) belonged to upper middle, and 18 (11\%) belonged to upper socioeconomic classes. Majority were born at term (91.5\%) with normal birth weight (78.1\%), were exclusively breastfed (92.1\%) in the first 6 months, and were completely immunized (97\%) for age as per national schedule. EVW was seen in 91 (55\%) and MTW in 74 (45\%) children. Median age was significantly higher in the MTW group. The two groups did not significantly differ in breastfeeding status, immunization status, prematurity, low birth weight, neonatal respiratory distress, bronchiolitis in infancy, age of onset, and duration of treatment ( - Table 1 ). The number of children on montelukast was higher in EVW group; those on inhaled corticosteroids (ICSs) were higher in MTW group and this finding was statistically significant. A significantly higher proportion of parental atopy and high absolute eosinophil count (AEC) was seen in children with MTW. Seasonality of exacerbation was present in 35 (47.3\%) children with MTW. Viral infections in 67 (90.5\%) children, dust allergy in 46 (62.1\%) children, environmental smoke exposure in 23 (31.1\%) children, and food allergens in 21 (28.3\%) children were the common triggers identified in MTW group. Out of 91 children with EVW, 79 (86.8\%) had well-controlled symptoms, whereas $12(13.2 \%)$ had uncontrolled symptoms. Among the 74 MTW, 58 (78.4\%) had well-controlled symptoms and $16(21.6 \%)$ had uncontrolled symptoms. There was no significant difference in the symptom control among EVW and MTW.

On univariate analysis of factors associated with symptom control in EVW group (-Table 2), it was found that children with either parent or both graduates had a higher percentage of uncontrolled symptoms with an odds ratio (OR) of 8.5 (95\% confidence interval [CI]: 2.2-32.1). Those with history of ocular/nasal allergies had more uncontrolled symptoms (OR: $12.8,95 \% \mathrm{CI}: 1.8-87.3)$. Other factors such as gender, SES, anthropometric parameters, prematurity, birth weight, breastfeeding, neonatal respiratory distress, bronchiolitis, environmental smoke exposure, AEC, and type and duration of treatment were not significantly associated. Among MTW ( - Table 3), only exclusive breastfeeding in the first 6 months of life predicted well-controlled symptoms (OR: $6.1,95 \% \mathrm{CI}$ : 1.2-30.9).

On univariate analysis among all participants ( - Table 4 ), wheezers with both parents being graduates had higher chance of having uncontrolled symptoms (OR: 2.5, 95\% CI: $1-5.9$ ), and so were those who had nasal/ocular allergy (OR: 2.5, 95\% CI: 1-5.9) and those not exclusively breastfed (OR: 5 , 95\% CI: 1.5-16.4). On multiple (binomial) logistic regression 
Table 1 General characteristics of the study population

\begin{tabular}{|c|c|c|c|c|}
\hline \multicolumn{2}{|l|}{ Variable } & $\begin{array}{l}\text { Episodic wheezer } \\
n=91(\%)\end{array}$ & $\begin{array}{l}\text { Multitrigger wheezer } \\
n=74(\%)\end{array}$ & p-Value (chi-square) \\
\hline \multicolumn{2}{|c|}{ Median age in mo (interquartile range) } & $36(24-48)$ & $42(36-54)$ & $0.003^{a}$ \\
\hline \multicolumn{2}{|l|}{ Male gender } & $64(70.3)$ & $46(62.2)$ & 0.268 \\
\hline \multicolumn{2}{|l|}{ Rural residence } & $52(57.1)$ & $46(62.2)$ & 0.514 \\
\hline \multirow[t]{5}{*}{ Socioeconomic status } & Lower & $2(2.2)$ & 0 & \multirow[t]{5}{*}{0.772} \\
\hline & Upper lower & $19(20.9)$ & $19(25.7)$ & \\
\hline & Lower middle & 39 (42.9) & $33(44.6)$ & \\
\hline & Upper middle & $21(23.1)$ & $14(18.9)$ & \\
\hline & Upper & $10(11)$ & $8(10.8)$ & \\
\hline \multicolumn{2}{|l|}{ Prematurity } & $8(8.8)$ & $6(8.1)$ & 0.876 \\
\hline \multicolumn{2}{|l|}{ Low birth weight } & $17(18.7)$ & $20(27)$ & 0.201 \\
\hline \multicolumn{2}{|c|}{ Exclusive breastfeeding for 6 mo } & $85(93.4)$ & $67(90.5)$ & 0.568 \\
\hline \multicolumn{2}{|c|}{$\begin{array}{l}\text { Median duration of breastfeeding in mo (inter- } \\
\text { quartile range) }\end{array}$} & $13(12-18)$ & $18(12-18)$ & $0.261^{\mathrm{a}}$ \\
\hline \multicolumn{2}{|l|}{ Complete immunization status } & $88(96.7)$ & $72(97.3)$ & 0.463 \\
\hline \multicolumn{2}{|l|}{ Neonatal respiratory distress } & $5(5.5)$ & $9(12.2)$ & 0.126 \\
\hline \multicolumn{2}{|l|}{ Bronchiolitis in infancy } & $47(51.6)$ & $32(43.2)$ & 0.282 \\
\hline \multicolumn{2}{|c|}{$\begin{array}{l}\text { Median age of symptom onset in mo (inter- } \\
\text { quartile range) }\end{array}$} & $10(6-18)$ & $12(5.75-25)$ & $0.547^{a}$ \\
\hline \multirow[t]{2}{*}{ Frequency of exacerbations } & $\leq 2$ in $6 \mathrm{mo}$ & $17(18.7)$ & $8(10.8)$ & \multirow[t]{2}{*}{$0.161^{b}$} \\
\hline & $>2$ in $6 \mathrm{mo}$ & $74(81.3)$ & $66(89.2)$ & \\
\hline \multirow[t]{3}{*}{ Controller medications } & Montelukast & $39(42.9)$ & $8(10.8)$ & \multirow[t]{3}{*}{$0.001^{b}$} \\
\hline & ICS & $49(53.8)$ & $66(89.2)$ & \\
\hline & None & $3(3.3)$ & 0 & \\
\hline \multicolumn{2}{|c|}{$\begin{array}{l}\text { Median duration of treatment in mo (inter- } \\
\text { quartile range) }\end{array}$} & $3(3-6)$ & $3.5(3-8.25)$ & $0.119^{\mathrm{a}}$ \\
\hline \multicolumn{2}{|c|}{$\begin{array}{l}\text { Median absolute eosinophil count (interquartile } \\
\text { range })^{c}\end{array}$} & $292(132.5-485)$ & $850(260-1,630)$ & $0.001^{\mathrm{a}}$ \\
\hline \multicolumn{2}{|l|}{ H/o atopic eczema } & $2(2.2)$ & $16(21.6)$ & $0.001^{\mathrm{b}}$ \\
\hline \multicolumn{2}{|l|}{ H/o ocular/nasal allergy } & $5(5.5)$ & $34(45.9)$ & $0.001^{\mathrm{b}}$ \\
\hline \multicolumn{2}{|l|}{ Parental atopy } & $12(13.2)$ & $44(59.5)$ & $0.001^{b}$ \\
\hline
\end{tabular}

Abbreviations: H/o, history of; ICS, inhaled corticosteroid.

a $p$-Value calculated using Mann-Whitney's $U$ test.

${ }^{\mathrm{b}} \mathrm{p}$ Value calculated using chi-square test.

'For 94 children.

in the EVW group, absence of ocular/nasal allergies predicted well-controlled symptoms (OR: 20.4, 95\% CI: 1.9-216.6). On multiple (binomial) logistic regression analysis among preschool wheezers in general, exclusive breastfeeding in the first 6 months of life predicted well-controlled symptoms (OR: 4.1, 95\% CI: 1.2-14.4).

\section{Discussion}

From our study results, we find that EVW is the dominant phenotype. Children with MTW were older than EVW, were mostly on ICS, and had more parental atopy, personal atopy, and higher AEC. In the EVW group, symptoms were more likely to be significantly well controlled in the absence of ocular or nasal allergy. In preschool wheezers as a whole, exclusive breastfeeding in the first 6 months of life was associated with well-controlled symptoms.

It is generally known that the proportion of MTW increases and EVW decreases over time. ${ }^{12,13}$ In a study involving 109 children in the age group of 2 to 6 years, Schultz et al found that 35\% had EVW and 65\% had MTW at baseline and $31 \%$ had EVW, $47 \%$ had MTW, and $22 \%$ had no wheeze at 1-year follow-up. ${ }^{4}$ We did not find significant difference in the age of onset, frequency of exacerbations, or duration of treatment between EVW and MTW, but there was difference in the type of treatment, AEC, and parental 
Table 2 Sociodemographic, clinical, treatment-related factors, and comorbidities associated with symptom control among episodic wheezers

\begin{tabular}{|c|c|c|c|c|}
\hline Factors & $\begin{array}{l}\text { Well controlled } \\
(n=79)\end{array}$ & $\begin{array}{l}\text { Uncontrolled } \\
(n=12)\end{array}$ & $\begin{array}{l}\text { Odds ratio } \\
(95 \% \mathrm{Cl})\end{array}$ & $\begin{array}{l}\text { p-Value } \\
\text { (chi-square) }\end{array}$ \\
\hline Age > 3 y $(\%)$ & $36(45.6)$ & $2(16.7)$ & $0.2(0-1.1)$ & 0.059 \\
\hline Male (\%) & $56(70.9)$ & $8(66.7)$ & $1.2(0.3-4.4)$ & 0.745 \\
\hline Rural (\%) & $46(58.2)$ & $6(50)$ & $0.7(0.2-2.4)$ & 0.592 \\
\hline Lower SES (\%) & $19(24)$ & $2(16.7)$ & $0.6(0.1-3.1)$ & 0.726 \\
\hline Father’s education: graduate (\%) & $19(24)$ & $9(75)$ & $9.4(2.3-38.6)$ & 0.001 \\
\hline Mother's education: graduate (\%) & $19(24)$ & $8(66.7)$ & $6.3(1.7-23.3)$ & 0.005 \\
\hline Both parents' education: graduate (\%) & $15(19)$ & $8(66.7)$ & $8.5(2.2-32.1)$ & 0.001 \\
\hline Prematurity (\%) (missing-1) & $7(9)$ & $1(8.3)$ & $0.9(0.1-8.2)$ & 0.999 \\
\hline Low birth weight (\%) (missing-4) & $15(20)$ & $2(16.7)$ & $0.8(0.1-4)$ & 0.999 \\
\hline Exclusive breastfeeding (\%) & $75(95)$ & $10(83.3)$ & $3.7(0.6-23.1)$ & 0.177 \\
\hline Partial immunization (\%) & $3(3.8)$ & 0 & NA & 0.999 \\
\hline Neonatal RD (\%) & $4(5)$ & $1(8.3)$ & $1.7(0.1-16.6)$ & 0.515 \\
\hline Bronchiolitis in infancy (\%) (missing-3) & $40(51.3)$ & $7(70)$ & $2.2(0.5-9.2)$ & 0.327 \\
\hline Stunted (\%) & $6(7.6)$ & $2(16.6)$ & $2.4(0.4-13.7)$ & 0.284 \\
\hline Underweight (\%) & $20(25.3)$ & $2(16.6)$ & $0.6(0.1-2.9)$ & 0.723 \\
\hline H/o atopic eczema, rash, etc. (\%) & $2(2.5)$ & 0 & NA & 0.999 \\
\hline H/o nasal/ocular allergic symptoms (\%) & $2(2.5)$ & $3(25)$ & $12.8(1.8-87.3)$ & 0.015 \\
\hline Exposure to environmental smoke (\%) & $3(3.8)$ & $1(8.3)$ & $2.3(0.2-24.1)$ & 0.438 \\
\hline Family h/o allergy (\%) & $10(12.6)$ & $2(16.7)$ & $1.3(0.2-7.2)$ & 0.656 \\
\hline Treatment with inhaled corticosteroids (\%) (missing-4) & $43(54.4)$ & $6(50)$ & $1.3(0.4-4.5)$ & 0.634 \\
\hline Absolute eosinophil count $>500$ (\%) (missing-55) & $5(14.7)$ & 0 & NA & 0.999 \\
\hline Duration of treatment $>3$ mo (\%) (missing-3) & $31(40.8)$ & $5(41.7)$ & $1(0.3-3.5)$ & 0.999 \\
\hline
\end{tabular}

Abbreviations: $\mathrm{Cl}$, confidence interval; $\mathrm{H} / \mathrm{o}$, history of; NA, not available; RD, respiratory disease; SES, socioeconomic status.

Table 3 Sociodemographic, clinical, treatment-related factors associated with symptom control among multitrigger wheezers

\begin{tabular}{|l|l|l|l|l|}
\hline Factors & $\begin{array}{l}\text { Well controlled } \\
(\boldsymbol{n}=\mathbf{5 8})\end{array}$ & $\begin{array}{l}\text { Uncontrolled } \\
(\boldsymbol{n}=\mathbf{1 6})\end{array}$ & $\begin{array}{l}\text { Odds ratio } \\
(\mathbf{9 5 \%} \text { Cl) }\end{array}$ & $\begin{array}{l}\boldsymbol{p} \text {-Value } \\
\text { (chi-square) }\end{array}$ \\
\hline Age >3 y (\%) & $37(63.8)$ & $11(68.8)$ & $1.2(0.3-4)$ & 0.713 \\
\hline Male (\%) & $37(63.8)$ & $9(56.25)$ & $1.3(0.4-4.2)$ & 0.582 \\
\hline Rural (\%) & $37(63.8)$ & $9(56.25)$ & $0.7(0.2-2.2)$ & 0.582 \\
\hline Lower SES (\%) & $14(24.1)$ & $5(31.2)$ & $1.4(0.4-4.8)$ & 0.538 \\
\hline Father's education: graduate (\%) & $15(25.9)$ & $3(18.75)$ & $0.6(0.1-2.6)$ & 0.746 \\
\hline Mother's education: graduate (\%) & $16(27.6)$ & $3(18.8)$ & $0.6(0.1-2.4)$ & 0.747 \\
\hline Both parents' education: graduate (\%) & $13(22.4)$ & $3(18.8)$ & $0.8(0.2-3.2)$ & 0.999 \\
\hline Prematurity (\%) & $5(8.6)$ & $1(6.3)$ & $0.7(0-6.5)$ & 0.999 \\
\hline Low birth weight (\%) (missing-3) & $18(32)$ & $3(20)$ & $0.5(0.1-2.1)$ & 0.527 \\
\hline Exclusive breastfeeding (\%) & $55(94.8)$ & $12(75)$ & $6.1(1.2-30.9)$ & 0.035 \\
\hline Partial immunization (\%) & $1(1.7)$ & $1(6.3)$ & $3.8(0.2-64.3)$ & 0.388 \\
\hline Neonatal RD (\%) & $5(8.6)$ & $4(25)$ & $3.5(0.8-15.1)$ & 0.095 \\
\hline Bronchiolitis in infancy (\%) (missing-1) & $26(45.6)$ & $6(37.5)$ & $0.7(0.2-2.2)$ & 0.563 \\
\hline Stunted (\%) & $5(8.6)$ & $1(6.3)$ & $0.7(0-6.5)$ & 0.999 \\
\hline
\end{tabular}


Table 3 (Continued)

\begin{tabular}{|l|l|l|l|l|}
\hline Factors & $\begin{array}{l}\text { Well controlled } \\
(\boldsymbol{n}=58)\end{array}$ & $\begin{array}{l}\text { Uncontrolled } \\
(\boldsymbol{n}=16)\end{array}$ & $\begin{array}{l}\text { Odds ratio } \\
(95 \% \text { Cl) }\end{array}$ & $\begin{array}{l}\boldsymbol{p} \text {-Value } \\
\text { (chi-square) }\end{array}$ \\
\hline Underweight (\%) & $11(19)$ & $5(31.3)$ & $1.9(0.5-6.7)$ & 0.315 \\
\hline H/o skin atopy (\%) & $14(24.1)$ & $1(6.3)$ & $0.4(0.1-2.2)$ & 0.496 \\
\hline H/o nasal and ocular allergy (\%) & $26(44.8)$ & $8(50)$ & $1.2(0.4-3.7)$ & 0.713 \\
\hline Exposure to environmental smoke (\%) & $19(32.8)$ & $4(25)$ & $0.6(0.2-2.4)$ & 0.762 \\
\hline Family h/o allergy (\%) & $36(62)$ & $8(50)$ & $0.6(0.2-1.8)$ & 0.384 \\
\hline Treatment with inhaled corticosteroids (\%) (missing-1) & $50(87.7)$ & $15(93.7)$ & $0.4(0-4.1)$ & 0.676 \\
\hline Absolute eosinophil count $>500$ (\%) (missing-41) & $19(73)$ & $3(43)$ & $0.2(0-1.5)$ & 0.186 \\
\hline Duration of treatment $>3$ mo (\%) (missing-1) & $28(49.1)$ & $9(56.3)$ & $1.3(0.4-4)$ & 0.614 \\
\hline
\end{tabular}

Abbreviations: $\mathrm{Cl}$, confidence interval; $\mathrm{H} / \mathrm{o}$, history of; $\mathrm{RD}$, respiratory disease; SES, socioeconomic status.

Table 4 Sociodemographic, clinical, treatment-related factors, and comorbidities associated with symptom control among wheezers in general

\begin{tabular}{|c|c|c|c|c|}
\hline Factors & $\begin{array}{l}\text { Well controlled } \\
(n=137)\end{array}$ & $\begin{array}{l}\text { Uncontrolled } \\
(n=28)\end{array}$ & $\begin{array}{l}\text { Odds ratio } \\
(95 \% \mathrm{Cl})\end{array}$ & $\begin{array}{l}p \text {-Value } \\
\text { (chi-square) }\end{array}$ \\
\hline Age > 3 y (\%) & $73(53.2)$ & $13(46.4)$ & $0.7(0.3-1.7)$ & 0.508 \\
\hline Male (\%) & $93(67.8)$ & $17(60.7)$ & $1.3(0.6-3.1)$ & 0.463 \\
\hline Rural (\%) & $83(61.3)$ & $15(53.5)$ & $0.7(0.3-1.7)$ & 0.491 \\
\hline Lower SES (\%) & $33(24)$ & $7(25)$ & $1(0.4-2.7)$ & 0.918 \\
\hline Father's education: graduate (\%) & $34(24.8)$ & $12(42.8)$ & $2.2(0.9-5.2)$ & 0.052 \\
\hline Mother's education: graduate (\%) & $35(25.5)$ & $11(39.2)$ & $1.8(0.8-4.4)$ & 0.140 \\
\hline Both parents' education: graduate (\%) & $28(20.4)$ & $11(39.2)$ & $2.5(1-5.9)$ & 0.032 \\
\hline Prematurity (\%) (missing-1) & $12(8.8)$ & $2(7.1)$ & $0.8(0.1-3.7)$ & 0.999 \\
\hline Low birth weight (\%) (missing-7) & $33(25.2)$ & $5(18.5)$ & $0.6(0.2-1.9)$ & 0.460 \\
\hline Exclusive breastfeeding (\%) & $130(95)$ & $22(78.5)$ & $5(1.5-16.4)$ & 0.01 \\
\hline Partial immunization (\%) & $4(2.9)$ & $1(3.5)$ & $1.2(0.1-11.4)$ & 0.999 \\
\hline Neonatal RD (\%) & $9(6.5)$ & $5(17.9)$ & $3(0.9-10)$ & 0.06 \\
\hline Bronchiolitis in infancy (\%) (missing-4) & $66(48.8)$ & $13(50)$ & $1(0.4-2.4)$ & 0.917 \\
\hline Stunted (\%) & $11(8)$ & $3(10.7)$ & $1.3(0.3-5.2)$ & 0.709 \\
\hline Underweight (\%) & $31(22.6)$ & $7(25)$ & $1.1(0.4-2.9)$ & 0.786 \\
\hline H/o atopy (eczema, rash, etc.) (\%) & $16(11.6)$ & $2(7.1)$ & $0.5(0.1-2.6)$ & 0.741 \\
\hline H/o nasal and ocular allergic symptoms (\%) & $28(20.4)$ & $11(39.2)$ & $2.5(1 .-5.9)$ & 0.032 \\
\hline Exposure to environmental smoke (\%) & $22(16)$ & $5(17.8)$ & $1.1(0.3-3.3)$ & 0.783 \\
\hline Family h/o allergy (\%) & $46(33.5)$ & $10(35.7)$ & 1. $(0.4-2.5)$ & 0.828 \\
\hline Treatment with inhaled corticosteroids (\%) (missing-5) & $93(70.4)$ & $21(75)$ & $0.8(0.3-2)$ & 0.629 \\
\hline Absolute eosinophil count $>500$ (\%) (missing-92) & $24(40)$ & $3(23)$ & $0.4(0.1-1.8)$ & 0.348 \\
\hline Duration of treatment $>3$ mo (\%) (missing-4) & $59(44)$ & $14(50)$ & $1.2(0.5-2.8)$ & 0.586 \\
\hline
\end{tabular}

Abbreviations: $\mathrm{Cl}$, confidence interval; $\mathrm{H} / \mathrm{o}$, history of; $\mathrm{RD}$, respiratory disease; SES, socioeconomic status.

atopy. Mutti et al in their study on 55 children have reported no significant difference between the age of onset, atopic status, and airway eosinophilia in EVW compared with MTW. ${ }^{14}$ Significantly higher AEC and family history of atopy were seen in MTW in our study as MTW represents an atopic phenotype..$^{5,12,13,15-18}$ On univariate analysis, we found that more children whose parents were graduates had uncontrolled symptoms. These children also had higher parental allergy and environmental smoke exposure. Previous studies have found that parental allergies were independent risk 
factors for developing persistent wheeze. ${ }^{19,20}$ It is also known that lower parental education and low SES are associated with poorer symptom control. ${ }^{19,21}$ However, in our study, we find that parents who were graduates were a risk factor for uncontrolled symptom on univariate analysis, but it was not confirmed in multiple logistic regression indicating that the discrepancy may be probably due to confounders. We also found that EVW without ocular/nasal allergy were more likely to have well-controlled symptoms. It is a well-known fact that allergic rhinitis can have a negative effect on symptom control. ${ }^{22}$ Although atopy is more often associated with MTW, in our study, we found they may be associated with EVW also and further serves to support the observations of the ERS Task Force statement that there may be overlap between the two phenotypes. ${ }^{2}$ Consistent with the conclusions of previous studies, ${ }^{23-25}$ we also found that exclusive breastfeeding predicted well-controlled symptoms in all preschool wheezers in general.

The limitations of our study are that the sample was drawn from an asthma clinic and not from the community. It was a cross-sectional design and AEC was not available for 92 children. Information regarding breastfeeding and immunization was obtained based on history obtained from parents and information available in the case records (for immunization).

\section{Conclusion}

To conclude, EVW is the dominant wheezing phenotype found in preschool children. Children with MTW phenotype tend to be older than EVW phenotype and tend to have higher AECs. Atopy in the form of ocular and nasal allergies can also be seen in children with EVW and its absence predicts well-controlled symptoms. Exclusive breastfeeding predicts well-controlled symptoms in children with preschool wheeze in general irrespective of the phenotypes.

\section{Authors' Contributions}

Both the authors were involved in the study design, data collection, analysis, literature review, and drafting of the manuscript, and reviewed the manuscript for intellectual content and seen and approved the final draft. The authors agree to be accountable for all aspects of the work in ensuring that questions related to the accuracy or integrity of any part of the work are appropriately investigated and resolved.

\section{Conflict of Interest \\ None declared.}

\section{References}

1 Beigelman A, Bacharier LB. Management of preschool children with recurrent wheezing: lessons from the NHLBI's asthma research networks. J Allergy Clin Immunol Pract 2016;4(01): $1-8$, quiz 9-10

2 Brand PLP, Baraldi E, Bisgaard H, et al. Definition, assessment and treatment of wheezing disorders in preschool children: an evidence-based approach. Eur Respir J 2008;32(04):1096-1110
3 Schultz A, Brand PLP. Episodic viral wheeze and multiple trigger wheeze in preschool children: a useful distinction for clinicians? Paediatr Respir Rev 2011;12(03):160-164

4 Schultz A, Devadason SG, Savenije OEM, Sly PD, Le Souëf PN, Brand PLP. The transient value of classifying preschool wheeze into episodic viral wheeze and multiple trigger wheeze. Acta Paediatr 2010;99(01):56-60

5 van Wonderen KE, Geskus RB, van Aalderen WMC, et al. Stability and predictiveness of multiple trigger and episodic viral wheeze in preschoolers. Clin Exp Allergy 2016;46(06):837-847

6 Spycher BD, Cochrane C, Granell R, et al. Temporal stability of multitrigger and episodic viral wheeze in early childhood. Eur Respir J 2017;50(05):1700014

7 Pin I, Siroux V, Boudier A, Vignoud-Nicollet L, Just J, Kauffmann F. Long-term evolution of virus-induced and multi-trigger wheeze in children of the EGEA study. Eur Respir J 2011;38:1507Q1Q2

8 Tagiyeva N, Devereux G, Fielding S, Turner S, Douglas G. Outcomes of childhood asthma and wheezy bronchitis. A 50-year cohort study. Am J Respir Crit Care Med 2016;193(01):23-30

9 Oberoi SS. Updating income ranges for Kuppuswamy's socioeconomic status scale for the year 2014. Indian J Public Health 2015;59(02):156-157

10 WHO. WHO Child Growth Standards: Methods and development [Internet]. WHO. Available at: http://www.who.int/childgrowth /standards/technical_report/en/. Accessed January 28, 2018

11 GINA_Report_2015_Aug11-1.pdf [Internet]. Available at: http:// ginasthma.org/wp-content/uploads/2016/01/GINA_Report_2015_Aug11-1.pdf. Accessed January 28, 2018

12 Just J, Saint-Pierre P, Gouvis-Echraghi R, et al. Wheeze phenotypes in young children have different courses during the preschool period. Ann Allergy Asthma Immunol 2013;111(04): 256-261.e1

13 Jurca M, Pescatore AM, Goutaki M, Spycher BD, Beardsmore CS, Kuehni CE. Age-related changes in childhood wheezing characteristics: a whole population study. Pediatr Pulmonol 2017;52(10):1250-1259

14 Mutti E, Baraldo S, Bazzan E, et al. Defining phenotypes of wheeze at preschool age: comparison of episodic vs. multitrigger wheeze. Eur Respir J 2014;44:429Q3Q4

15 Ulrik CS. Peripheral eosinophil counts as a marker of disease activity in intrinsic and extrinsic asthma. Clin Exp Allergy 1995; 25(09):820-827

16 Castro-Rodríguez JA, Holberg CJ, Wright AL, Martinez FD. A clinical index to define risk of asthma in young children with recurrent wheezing. Am J Respir Crit Care Med 2000;162(4 Pt 1):1403-1406

17 Kurukulaaratchy RJ, Fenn M, Matthews S, Arshad SH. Characterisation of atopic and non-atopic wheeze in 10 year old children. Thorax 2004;59(07):563-568

18 de Sousa RB, Medeiros D, Sarinho E, Rizzo JÂ, Silva AR, Bianca ACD. Risk factors for recurrent wheezing in infants: a case-control study. Rev Saude Publica 2016;50:15

19 Taylor-Robinson DC, Pearce A, Whitehead M, Smyth R, Law C. Social inequalities in wheezing in children: findings from the UK Millennium Cohort Study. Eur Respir J 2016;47(03):818-828

20 Caudri D, Savenije OEM, Smit HA, et al. Perinatal risk factors for wheezing phenotypes in the first 8 years of life. Clin Exp Allergy 2013;43(12):1395-1405

21 Uphoff E, Cabieses B, Pinart M, Valdés M, Antó JM, Wright J. A systematic review of socioeconomic position in relation to asthma and allergic diseases. Eur Respir J 2015;46(02):364-374

22 ( NEW) 2017 GINA Report: Global Strategy for Asthma Management and Prevention [Internet]. Global Initiative for Asthma -GINA Available at: http://ginasthma.org/2017-gina-reportglobal-strategy-for-asthma-management-and-prevention/. Accessed January 4, 2018

23 Guibas GV, Xepapadaki P, Moschonis G, et al. Breastfeeding and wheeze prevalence in pre-schoolers and pre-adolescents: the Genesis and Healthy Growth studies. Pediatr Allergy Immunol 2013;24(08):772-781 
24 den Dekker HT, Sonnenschein-van der Voort AMM, Jaddoe VWV, Reiss IK, de Jongste JC, Duijts L. Breastfeeding and asthma outcomes at the age of 6 years: the Generation R Study. Pediatr Allergy Immunol 2016;27(05):486-492
25 Sonnenschein-van der Voort AMM, Jaddoe VWV, van der Valk RJP, et al. Duration and exclusiveness of breastfeeding and childhood asthma-related symptoms. Eur Respir J 2012;39 (01):81-89 